\title{
¿ES POSIBLE AGILIZAR LA VIA DE APREMIO?
}

\author{
ANTONIO NAVAS SEGURA
}

Prof. Asociado Derecho Civil

\section{SUMARIO:}

I.- JUSTIFICACION.

II.- TRAMITES DE EJECUCION DE SENTENCIA, ACTUALMENTE.

1.- En cuanto al avalúo y cargas.

2.- Comentario.

III.- REFORMA QUE SE PROPONE.

IV.- GARANTIAS.

1.- En cuanto al deudor.

2.- En cuanto a la publicidad respecto a los acreedores.

V.- CONCLUSIONES.

\section{I.- JUSTIFICACION.}

Las presentes notas no pretenden ser un estudio sobre la ejecución de sentencia, sino una aportación, aunque sea rudimentaria, vista por un abogado que día a día tiene que enfrentarse a los múltiples trámites que aquella lleva consigo y que podrían ser simplificables.

En una posible reforma de la Ley de Enjuciamiento Civil podría permitirse una mayor participación a la actividad de las partes, realizando estas algunas actuaciones que hoy se efectúan a través de peticiones al Juzgado, y que acelerarían los procedimientos.

Esas notas queremos centrarlas en aquellas ejecuciones en que los bienes trabados pertenecen, como dice la Ley de Ritos, a la clase de los inmuebles.

Lógicamente los redactores de la Ley adjetiva tenían como misión fundamental que en una ejecución de sentencia, además de garantizar el cobro de su crédito por los acreedores, quedarán salvaguardados los intereses de los deudores, pero la cantidad de procedimientos que se turnan diariamente en los Juzgados, el trabajo que pesa sobre la oficina judicial, y en general, por la causa que sea, pues tampoco vamos ahora a analizarla, cuando se entra en la ejecución empieza lo que podemos denominar un verdadero viacrucis, hasta el cobro total, si se llega a ello, de las cantidades adeudadas. 
Esta larguísima tramitación en verdad no beneficia a nadie, ni al acreedor porque cuando pecibe el importe de su crédito, con la lógica devaluación progresiva de la moneda, ha perdido poder adquisitivo, ni al deudor porque la acumulación de intereses hacen que la deuda inicial se duplique o triplique, o en algunos casos sea mayor aún la proporción, pensemos en procedimientos de entidades de crédito, actualmente la mayoría, en que los intereses de demora están pactados, y casi siempre ronda el $20 \%$.

La lentitud en una ejecución, repetimos, no beneficia a nadie, pero además tenemos, y esto a mi juicio es lo más importante, la paulatina pérdida de confianza en las reclamaciones judiciales, y la administración de justicia es la base en todo estado de derecho.

\section{II.- TRAMITES DE EJECUCION DE SENTENCIA, ACTUALMENTE.}

Vamos a entrar ya en lo que es la ejecución de la sentencia, para a continuación exponer lo que podría ser en un futuro, si estas notas sirven para una reflexión.

1.- En cuanto al avalúo y cargas.

Actualmente, si los bienes pertenecen a la clase de los inmuebles, por utilizar la expresión del art. 1.489, encontramos la siguiente tramitación:

A) El ejecutante interesa al Juzgado, que lo expide, mandamiento dirigido al Registro de la Propiedad donde estén inscritas las fincas embargadas para que libre certificación en la que se hará constar las hipotecas, censos y gravémenes a que están afectados los bienes, o se certifique la libertad de ellos.

Al mismo tiempo, se requerirá al deudor para que en el plazo de seis días presente en la Escribanía los títulos de propiedad de las fincas (art. 1.489).

B) Una vez certificadas cargas, si los inmuebles estuviesen gravados con segundas o posteriores hipotecas, no canceladas, se hará saber a los acreedores hipotecarios para que puedan participar en el avalúo y subasta (art. 1.490).

C) Para el avalúo de los bienes se designa un perito por el ejecutante y se da conocimiento al deudor para que, si le interesa, nombre otro en el plazo de dos días bajo apercibimiento de tenerle por conforme con el designado.

Puede que al recibir esta notificación el ejecutado se persone en autos y designe otro, mándandose entonces que acepte el cargo, y si no lo acepta se requerirá al demandado para que nombre un segundo, y si tampoco aceptase se hará la valoración por el nombrado por el ejecutante, pudiendo el juez nombrar otro.

Hecha la valoración se solicitará la subasta.

\section{2.- Comentario.}

Lo expuesto nos lleva a que una ejecución se prolongue más de un año, con el consiguiente aumento de la deuda, para el ejecutado, por los intereses y la pérdida del poder adquisitivo para el acreedor por la depreciación lógica de la moneda, es decir, a nadie interesa que una ejecución se prolongue tanto tiempo.

Como decíamos al principio, todos esos trámites previstos en la Ley de 
Enjuiciamiento Civil están ordenados a que exista una garantía para el ejecutado (posibilidad de intervenir en el avalúo) y para los titulares de derechos reales de garantía sobre los inmuebles que se ejecutan, (la notificación a acreedores con segundas o posteriores hipotecas) para que puedan subrogarse en el crédito del actor, previo su pago y también participar en el avalúo de los bienes.

Pero lo que también es cierto es que en la época en que se promulgó la L.E.C., no había tanta litigiosidad, y las ejecuciones de las sentencias eran contadas; es más, tampoco hay que remontarse a finales del siglo pasado, hace 15 ó 20 años eran escasos los procedimientos tanto declarativos como ejecutivos que se solucionaban con la subasta de los bienes, sin embargo hoy es más fácil que se acabe un procedimieto con la subasta a que se solucione al dictarse sentencia o inmediatamente después de solicitarse la ejecución.

Ello hace que se imponga una reforma en los trámites que aseguren una más eficaz tramitación, sin que exista incompatibilidad entre la rapidez y las garantías antes aludidas, para el ejecutado y terceros.

\section{III.- REFORMA QUE SE PROPONE}

El decir que la Ley debe salvaguardar las garantías de los ejecutados, y dar más cabida a la actividad de las partes no significa un contrasentido, ya que ambas cosas son totalmente compatibles, y en ello se fundamenta este trabajo.

No voy a efectuar una redacción de lo que podrían ser los preceptos de la Ley de Enjuiciamiento Civil, sino aportar unas ideas para que de ser acogidas, al menos en parte, sean una ayuda al redactar los preceptos adjetivos.

Una vez dictada la sentencia, el actor podría presentar escrito al Juzgado al que acompañará certificación expedida por el Registro de la Propiedad, solicitada (por el acreedor sin intervención judicial) con fecha posterior a la firmeza de la resolución judicial, en la que se haga constar las cargas que pesan sobre el inmueble sobre el que se ha practicado el embargo y la naturaleza de estas.

Si de dicha certificación aparecieren los bienes gravados con segundas o posteriores hipotecas se acompañará copia de Acta notarial en la que se haga constar haber notificado a los acreedores inscritos con dichas hipotecas la existencia del procedimiento y si quieren hacer efectiva la deuda con subrogación en el crédito del actor o participar en el avalúo, siendo estos requerimientos de fecha posterior a la certificación expedida por el Sr. Registrador de la Propiedad.

Al mismo tiempo, y también de fecha posterior se presentará valoración efectuada por perito, de los bienes embargados y Acta notarial notificando al deudor el perito designado y la valoración efectuada, para que en el plazo de cinco días pueda presentar otra valoración realizada por otro perito elegido por él. Si ambas valoraciones no excediesen de un $10 \%$ se fijará como precio de subasta el mayor, y si excediese de ese porcentaje el Juzgado designará un tercero cuya valoración será el tipo de subasta.

Transcurrido el pazo que se conceda en el Acta de notificación al deudor, el acreedor podrá solicitar la subasta de los bienes. 
Conscientes de que este sistema en algunos casos puede plantear alguna dificultad sobre notificaciones, nada impide que puedan subsistir ambos sistemas, el actual y el que se propone, a elección del actor, como actualmente se da en el procedimento especial sumario del art. 131 de la Ley Hipotecaria, en el que el acreedor puede realizar el requerimiento de pago, bien notarialmente o bien dentro del mismo procedimiento.

\section{IV.- GARANTIAS}

\section{1.- En cuanto al deudor.}

Ya hemos dicho anteriormente, que el trámite de ejecución de sentencia tiene que velar por las garantías de los deudores, para lo que existe la fe pública judicial en todas las actuaciones, -intervención del secretario-; lo que se propone es que se dé la misma fé pública, sustituyendo al Secretario Judicial por un Notario, con lo que las garantías tanto frente al deudor como ante terceros acreedores no se ven lesionadas en ningún momento, incluso podría extenderse la notificación a aquellos acreedores posteriores que no lo fueran por hipotecas, sino por embargos como ocurre en el procedimiento especial sumario del art. 131 de la Ley Hipotecaria.

La intervención del Notario es suficiente garantía, aumentándose aún bajo la supervisión judicial del cumplimiento de los requisitos previstos en la Ley.

Esta actuación notarial y validez de las notificaciones existe ya en el procedimiento ejecutivo extrajudicial previsto en la Ley Hipotecaria, en el que a los acreedores posteriores se les efectúa las notificaciones a través del Notario, al igual que, como hemos dicho, en el procedimiento especial sumario previsto en el artículo 131 de la Ley Hipotecaria, el requerimiento de pago al deudor puede hacerse en el mismo procedimiento o acreditar haberlo hecho realizado con anterioridad de forma notarial.

Ahora bien, donde más garantía ofrece, a nuestro juicio, este sistema es en lo concerniente a la valoración de los bienes, porque en realidad a un deudor le tiene sin cuidado quién va a ser el perito que valore sus bienes, salvo que hubiese una enemistad personal entre ambos, cosa casi improbable. Lo que realmente le interesa es el valor que se va a dar a esos bienes, y tal como está redactada hoy día la Ley de Enjuiciamiento Civil lo único que se notifica es quién es el perito designado por si el deudor quiere nombrar otro por su parte, y si no lo hace confiando en que se dará una valoración acorde con la que él considera su valor, puede éste perito nombrado por el acreedor hacer la valoración que estime conveniente sin posibilidad del ejecutado de presentar otra, tal vez más cerca de la realidad.

Al mismo tiempo se evitan las picarescas de algunos ejecutados que cuando se les notifica el nombramiento de perito, hacen la designación de otro que no acepte para que se le requiera de nombramiento de un segundo que tampoco acepta, alargando así un procedimiento, ya de por sí largo, siempre en perjuicio del acreedor.

Por otro lado, el principal interesado en que el procediminento se solucione rápidamente será el propio acreedor, por lo que pondrá la máxima diligencia en cumplimentar los trámites que se han apuntado. 
Y por último, en cuanto a beneficiados, nos encontramos con el propio deudor que tiene conocimiento puntual y exacto del valor del inmueble antes de que sea solicitada la subasta con lo que podrá poner los medios necesarios para su verdadera valoración, y no como ocurre ahora, que si no nombra perito cuando se le notifica el designado por el acreedor, por estimar que la valoración va a ser la correcta, sólo tiene conocimiento del valor cuando se le notifica la fecha de la subasta y si tiene la precaución de examinar los autos; y la superbeneficiada es precisamente la administración de justicia, que sería mucho más ágil sin dejar de garantizar los intereses de los intervinientes en un procedimiento.

2.- En cuanto a la publicidad respecto a los acreedores.

La notificación se hacía personalmente o a través del procedimiento seguido a instancia del acreedor posterior en la persona del procurador de los tribunales que ostenta su representación, y, actualmente se efectúa también por carta certificada con acuse de recibo, que si bien no vamos a cuestionar la legalidad de este sistema, sí podemos afirmar que no es el más idoneo y produce grandes retrasos porque se puede dar, y de hecho se dá, extravíos en los acuses de recibo, con lo que si no consta en autos tiene que volver a realizarse.

También nos encontramos con que el destinatario puede estar ausente de su domicilio en horas de reparto, cosa bastante habitual, salvo que se trate de empresas, al coincidir el horario de reparto del servicio de correos con las jornadas laborales -es cada vez más frecuente que ambos cónyuges tengan una actividad laboral fuera del domicilio- con lo que al estar ausentes se deja nota para que el destinatario se persone en las oficinas de correos a retirar el certificado que si no se realiza en el plazo de 30 días es devuelto caducado, por lo que al no haberse efectuado la notificación debe realizarse de nuevo. Ello supone verdaderos retrasos en cumplimentar los trámites procesales $\mathrm{y}$, en consecuencia, del procedimiento.

Siendo el notario quien comparece y da fe de su entrega no existe extravío y si no se encuentra el destinatario en ese momento, realizará un segundo o un tercer intento en distintas horas hasta su notificación, ello en breves días con lo que se da una economía de tiempo.

\section{- CONCLUSIONES -}

PRIMERA.- La actividad de los interesados en la realización de actos conducentes a la aceleración de los procedimientos no es una novedad en nuestra legislación (art. 131 L.H.), lo que se propone es que se le de carta de naturaleza en la fase de ejecución de sentencia.

SEGUNDA.- El suplir esta actividad hoy reservada a la oficina judicial, a petición de parte, por la del propio interesado con unificación de trámites y conservándo las garantías de terceros y del propio ejecutado -intervención de notario-, haría más rápida y eficaz la ejecución de las sentencias, trámite donde hoy se producen los auténticos atrasos en los procedimientos. 
ADDENDA.- Ya en prensa este trabajo, por Ley 10/1992, de 30 de abril, de Medidas Urgentes de Reforma Procesal, se ha reformado, entre otros, el art. 1490 de la Ley de Enjuiciamiento Civil, quedando redactado como sigue:

"El Registrador de la Propiedad comunicará a los titulares de derechos que figuren en la certificación de cargas y que consten en asientos posteriores al del gravamen que se ejecuta, el estado de la ejecución para que puedan intervenir en el avalúo y subasta de los bienes, si les conveniere.

La comunicación se practicará en el domicilio que conste en el Registro por correo o telégrafo. En la certificación a que se refiere el artículo anterior se expresará al haberse practicado esta comunicación".

Se inicia un intento, aunque tímido, de desjudicializar algún trámite en la ejecución, como se propone en este trabajo. 